\title{
Empirical Evidence of Color on Motivation toward Learning
}

\author{
Bisma Laeeque \\ Email: bislaeeque@gmail.com \\ Asma Akmal \\ College of Home Economics, Gulberg Lahore
}

Received: January 28, 2017 Accepted: February 25, 2017 Published: April 19, 2017

doi:10.5296/ijld.v7i2.11044 URL: http://dx.doi.org/10.5296/ ijld.v7i2.11044

\begin{abstract}
This study was conducted to understand the role of color in motivating children towards learning. The sample was selected from two government schools of a village named Rao Khan Wala near Lahore. Traid color schemes were used as they provide a unique balance of both the cool and warm colors. Furthermore for the selection of the sample's age Piaget's theory of cognition was used and children falling in concrete operational stage were selected in this research. The study revolved around experimental research method in which the research was divided into two phases for data accumulation, the pre stage and post stage. The findings of the study revealed that colors positively increase children's motivation toward learning in classroom settings.
\end{abstract}

Keywords: Color, Motivation, Learning 


\section{Introduction}

Pakistan is among those countries where education system is not the same for all. Not only the medium of instruction differs but the facilities provided to the students vary greatly depending upon private and public sector. The students of private schools are the privileged class who not only have access to the best syllabus but also best infrastructure and class environment. Teachers of private schools put a lot of effort in order to make their class inviting and welcoming for the students. They are bound by their school administration to decorate their class at a minimum interval of two weeks and a maximum of a term, periodically to provide a welcoming atmosphere for their students, which also plays a pivotal role in their learning. Whereas on the other side of the picture the students from the rural areas are not so fortunate in this regard. They lack behind not only in the curriculum sphere but they face serious challenges regarding the classrooms, most of the times the classrooms do not exist and the students are bound to learn either by sitting under the naked sky in stifling hot summers or by using primitive material built- hatch like roofs to cover their heads. In the instances where the proper built classroom facility is available, the classrooms are so bland and boring that they fail to motivate the pupils to inhibit the space for efficient learning. The researcher while her data gathering was told by the Principal of one such Government school that it is a popular indigenous saying in their village "A bachelors from village is equivalent of matriculations from city". Throughout our lives human beings keep transforming the environment in which we live for our ease, facilitation and comfort. Environment is not confined to homes alone rather physical environment of a classroom also should be kept in mind when planning a classroom for children. Color is one such medium which if used creatively can provide motivation to students and the interventions which are panned with color are also less costly than any other component of physical environment.

Learning is a complex mental activity that involves cognitive processes (Estes 2014). Therefore Piaget's theory of cognition was used in this research to select the sample age on the grounds of their intellectual prowess. Children falling in concrete operational stage were selected age group (7 to 11years) as they have mastered most of their cognitive development except for the abstract thinking process which are initiated and mastered in the last stage of the theory that is formal operational stage. (Elliot and Maier 2007) It has been established by research that colors have a motivational impact on people. They are known to provide energy and vigor. Colors also participate in physiological process of human body. (Engelbrecht 2003) They have the ability to fasten or lower the heart beat, respiration and can cause fluctuations in blood pressure. A variety of colors schemes are established in which the interior designers and architects work. Triad, one such color scheme is which provides a delicate equilibrium between warm and cool colors which is used in this study. This research is focused on the significance of the ability of color to motivate students towards learning. Since previously no such study has been conducted in Pakistan which addresses this issue and provides answers to the challenges faced by the not so privileged class attending schools in rural areas of Pakistan. This research shall prove beneficial for the students of architecture and interior design as they shall get to understand the problems faced by the pupils in rural areas. For the school teachers who are faced with the task of motivating their students toward learning. Lastly also for the 
policy makers so that they may device some problem alleviating policies for such schools.

\subsection{Study Hypothesis}

H1: attendance of students was significantly better after applying colored intervention in classrooms.

$\mathrm{H} 2$ : term scores of students were significantly better after applying colored intervention in classrooms.

\subsection{Delimitations}

To observe the effect of color on children's motivation toward learning and to maximize control. No changes were made in furniture, arrangement of classroom, curriculum, timings of class, temperature of classroom, lighting, teachers, pedagogy or no heating cooling devices were introduced both in pre or post stage. Only impact of color was evaluated.

\section{Literature Review}

Classroom environment designed in harmony and coordination with curriculum yields better results in preschoolers. (Inan 2009). The physical environment of a classroom comprises of textures, furniture, color, lighting and other materials. A classroom where the physical environment is so planned that it carefully arranged and planned produces not only good results of children academically by enhancing their learning abilities but also trains their perceptual and motor skills. (Edwards 2002) In Reggio Emilia schools, learning environment is considered to be the third teacher which is pivotal for a smooth teaching learning process. Teachers are required to develop aesthetically pleasing learning environment which conveys strong messages and concepts being taught in classrooms, thus using classroom environment as pedagogical tool for maximum output. Each child masters cognitive development after passing through a series of stages gradually throughout his childhood (Piaget 2000) in his theory of cognition divided this journey into four successive stages. The development commences with sensorimotor stage in which the human child employs all his five senses to gain knowledge regarding the world in which he lives from birth till two years of age, after two till seven years another stage onsets which is called the pre-operational stage, in which the child becomes predominantly egocentric and starts conceptualizing things symbolically. From seven to eleven concrete operational stage starts in this stage the child marks the beginning of logical thought processing and achieve the prowess to process things in their head rather by the aid of physical stimulus. The last stage is formal operational stage eleven years onwards in this stage the child starts the abstract and rational thought processing and acquires the ability to logically process hypotheses.

Classroom physical environment plays a significant role in achieving better academic scores. (Suleman and Hussain 2014) conducted experimental research in Kohat, division Pakistan on the role of classroom environment in achievement of better scores. They concluded that a well organized, designed, decorated and facilitated classroom help achieves better academic results. (Engelbrecht 2003) in his study concluded that color has an impact on learning, color increases the functionality of learning environment and decreases the number of absent 
students. Color is linked with cognitive development of students and unconsciously plays a role in a child's development to an adult. (Torrice and Logrippo 1989). Colors have different psychological and physiological effect, warm colors can increase blood pressure, respiration and heart rate while on contrary cool colors have a vice versa effect. Warm colors tend to inculcate motivation, vigor and energy whereas cool colors are said to have cooling, soothing and comforting effect. A delicate equilibrium is essential to be observed in the use of warm and cool colors, for excess of warm can create hyperactivity and too much cool colors yield stagnation and boredom. Differences in gender had no effect on impact of color to motivate children (Karp and Karp 1988) concluded in their findings that the response of color stimuli in male and female children are same. (Mone 2002) performed a series of five experiments on children with black and white and colored images. He concluded that colored images had lasting impact on children's memory as compared to the black and white images. Colored images were easily recalled by the students and hence made a lasting impact on their memory as compared to black and white. (Allen 2011) in their research regarding classroom environment concluded that warm and cool colors have different physiological and psychological effect and the manipulation of color can help in development of concepts, behaviors and promote different education related activities.

\section{Method}

Non probability purposive sampling strategy was used in this study to gather data. A sample of $(\mathrm{N}=120)$ students were selected from two government schools of Rao Khan Wala comprising of sixty students in experimental group and sixty in control group. In both the groups 30 students were male and thirty were female. Only such schools were included in this study which was purpose built, fully functional, well equipped in terms that they have proper sitting provision for the students in form of chairs and tables and also had at least a black board. Those schools were not included in this study which had any of the above mentioned facility missing or was not in proper shape that it could be put to use. Soft board or green boards were even not present in the schools which were found to have all the aforementioned characteristics. After finding the schools which fulfilled the stipulated criteria for this research, permission was sought from their head master and head mistress as this study involved renovation of their classes which could not be made without their permission.

The research design of this study was experimental in which the attendance and term results of the students were analyzed before and after the intervention. Furthermore data was also directly obtained from the students by distribution of questionnaires both before and after. Students learning motivation questionnaire developed by (Dowling 2011) was used after adaptation. Before the full scale use of questionnaire a pilot study was conducted to establish the reliability of the tool and after the reliability analysis .78 was established of the tool which is acceptable according to international standards. Four classes were taken for this research. Two of which were of boys and two of girls. Furthermore section A of each class was taken as control group and section B as experimental group. In this manner two classrooms went through the program intervention phase whereas the control group remained just the way they were. In September the pre test phase the researcher collected attendance sheets and term report list from the respective class teachers and also asked students to fill in 


\section{Macrothink}

the questionnaire which was centered around their views regarding color and class decoration. After a month program in October the intervention was introduced. Their classrooms were repainted and decorated around the themes extracted from their syllabus as the literature supported the claim that colored images and decorations had lasting impact on children's memory and helped to reinforce the concept that they were learning in the class as it brought a real time effect into an otherwise abstract phenomena. The walls of the classroom were painted in neutral colors mainly off white and the rest of the decorations were made with triad color scheme, in case of girls red, yellow and blue while in boys red orange, yellow green and blue violet. 3D models, drawings, muriels were erected on the walls and around the black board around the themes taken from their curriculum. No changes were made in the furniture, lighting, sitting arrangement, heating or cooling devices, teachers, curriculum, pedagogy or any other feature to maximize control. After the intervention the researcher again collected attendance sheets, second term report lists and once again asked the children to fill in the questionnaire in January. However this time the questionnaire was modified a bit by replacing a few words with their synonymous to eliminate the conditioning effect in children. The response rate was $98.33 \%$ and hence after the completion of data accumulation the data was analyzed using SPSS 20(Statistical Package for Social Sciences) and results were generated.

\section{Data Analysis}

Table 4.1.Before and after attendance of experimental group students (males).

Gender

males
Attendance Before

$89 \%$

\section{Attendance After}

$94 \%$

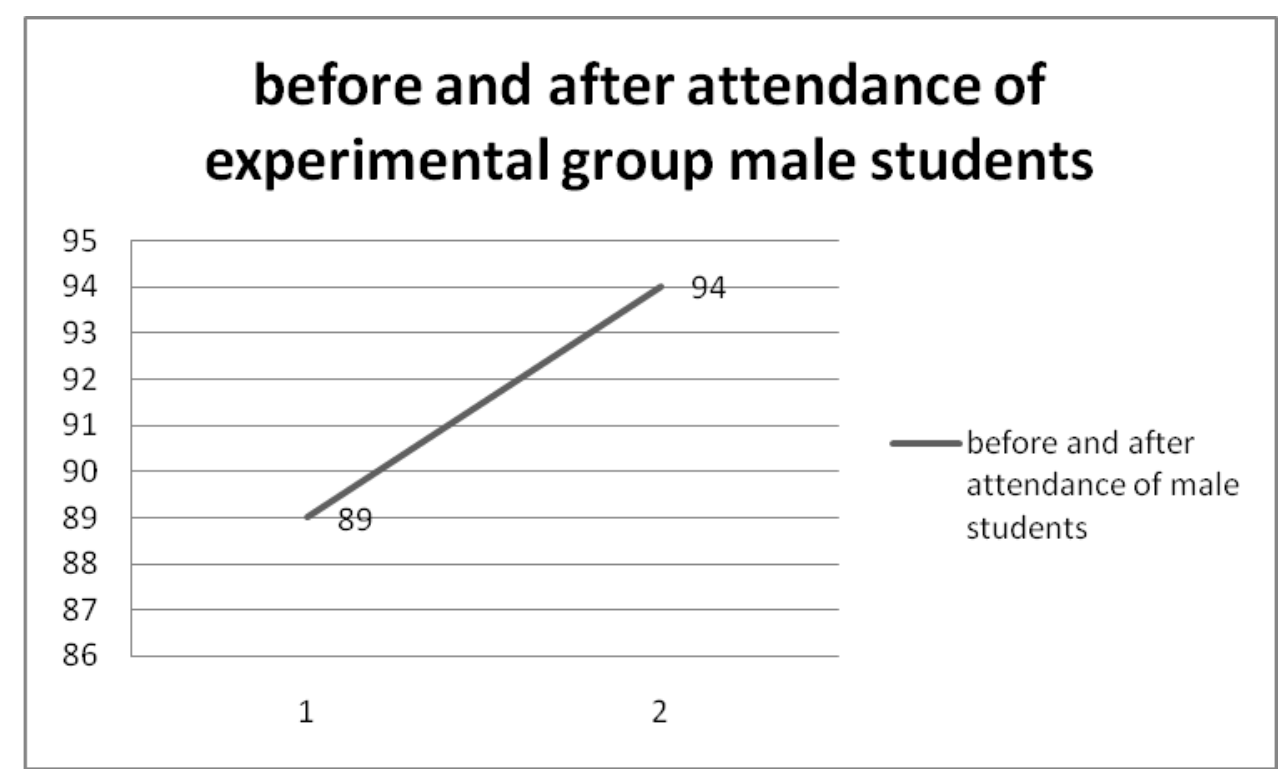

Fig 4.1.Before and after attendance of male students. 


$\begin{array}{rr}\text { Macrothink } & \text { International Journal of Learning and Development } \\ \text { ISSN 2164-4063 } \\ \text { Instrtute }\end{array}$

Table 4.2 Before and after attendance of control group students (males).

Gender Attendance Before Attendance After

$\begin{array}{lll}\text { Males } & 90 \% & 90 \%\end{array}$

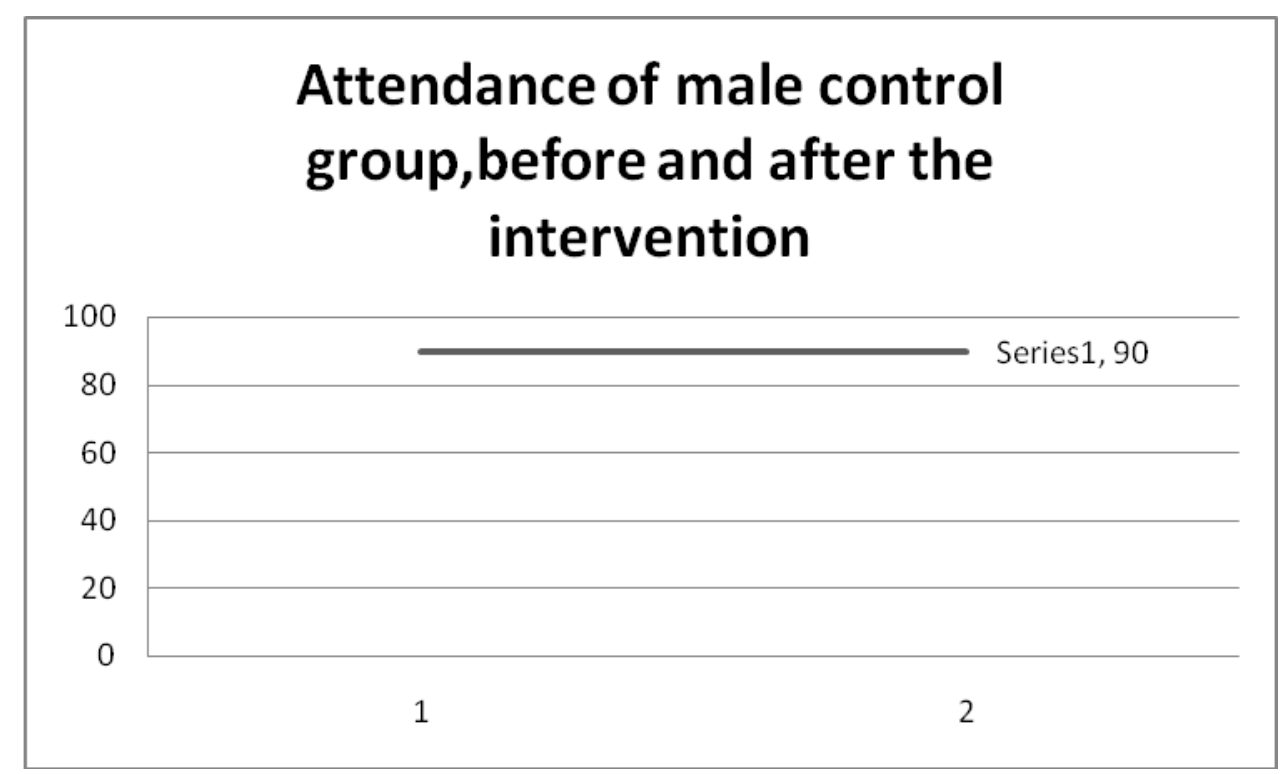

Fig4.2.Attendance of male students- before and after.

Table 4.3.Attendance of experimental group female students before and after the intervention.

Gender

Females
Attendance Before

$87 \%$
Attendance After

$92 \%$ 


\section{before and after attendance of experimental group female students}

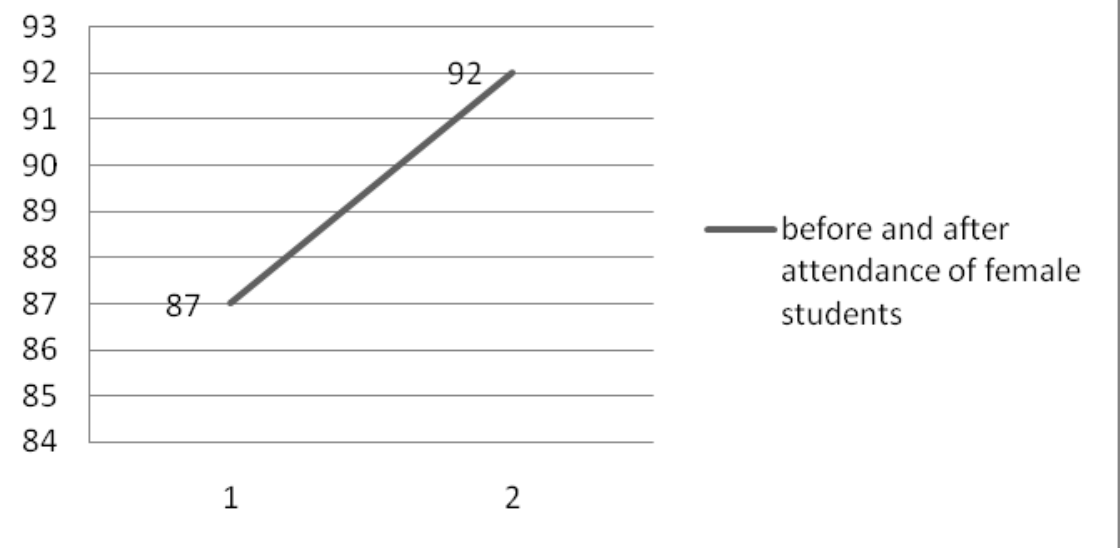

Fig.4.3.Attendance of female students- before and after.

Table 4.4.Attendance of control group female students before and after the intervention.

Gender

Females
Attendance Before

$85 \%$
Attendance After

$83 \%$

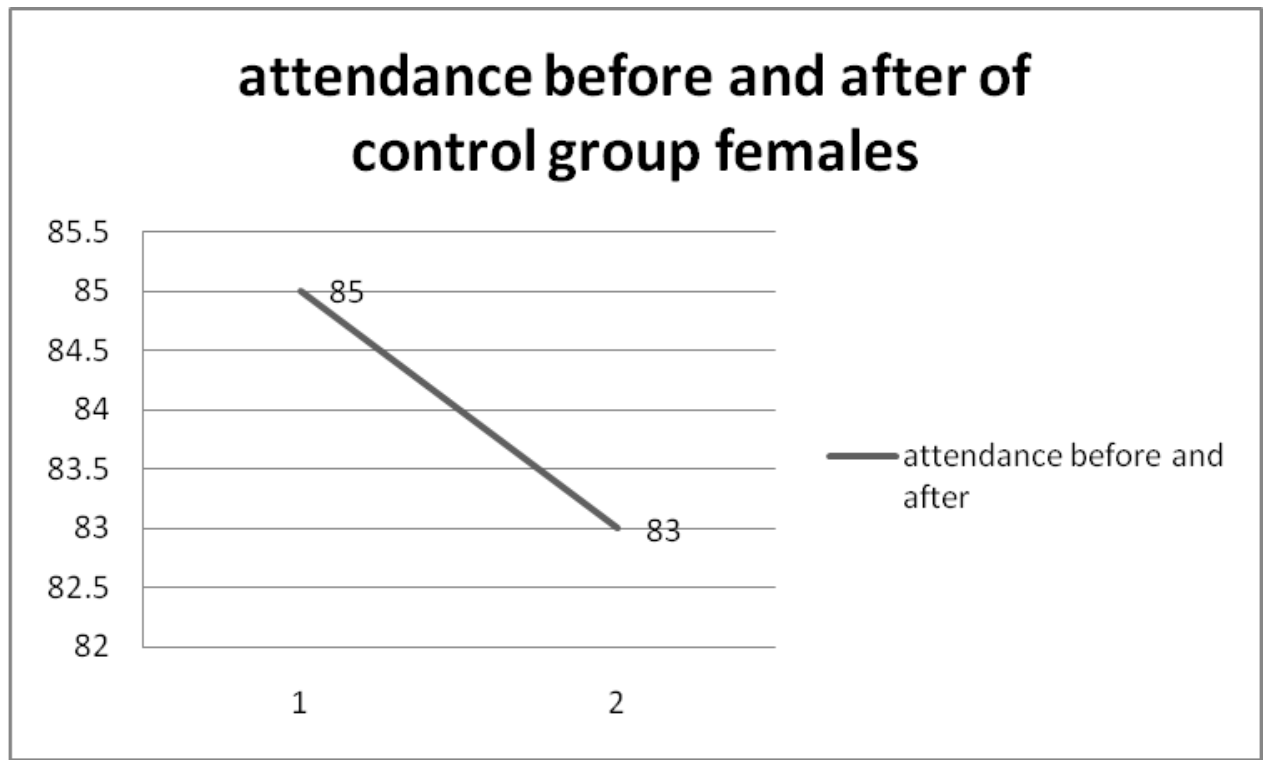

Fig. 4.4.Attendance of female students (control group)- before and after. 


\section{Macrothink}

Table 4.5.Pass percentage of experimental group (both males and females) before and after the intervention.

Before

51
After

55

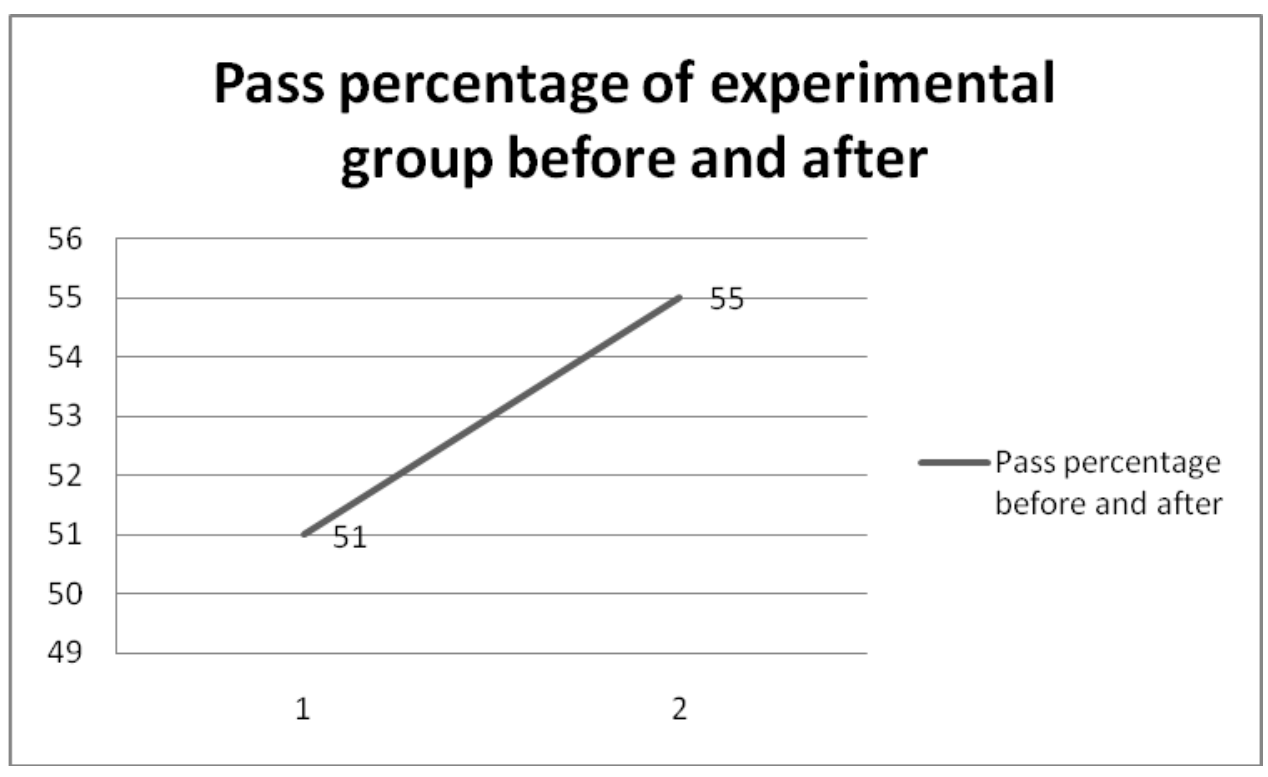

Fig 4.5 Experimental group pass percentage of students before and after.

Table 4.6.Pass percentage of control group (both male and female) before and after the intervention.

Before

53
After

53 


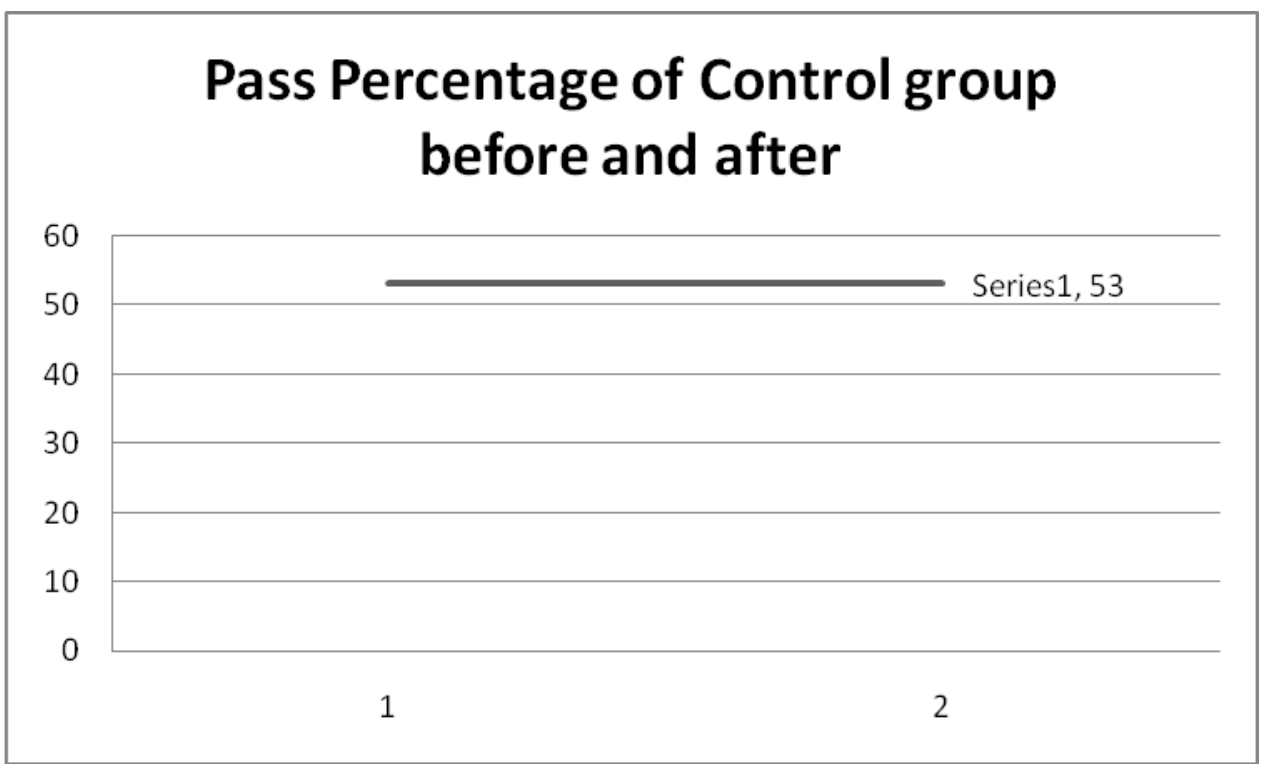

Fig 4.6 Experimental group pass percentage of students before and after.

Table 4.7 Percentage of students who feel active in class after intervention

\begin{tabular}{|l|l|}
\hline activeness since décor & $61 \%$ \\
\hline
\end{tabular}

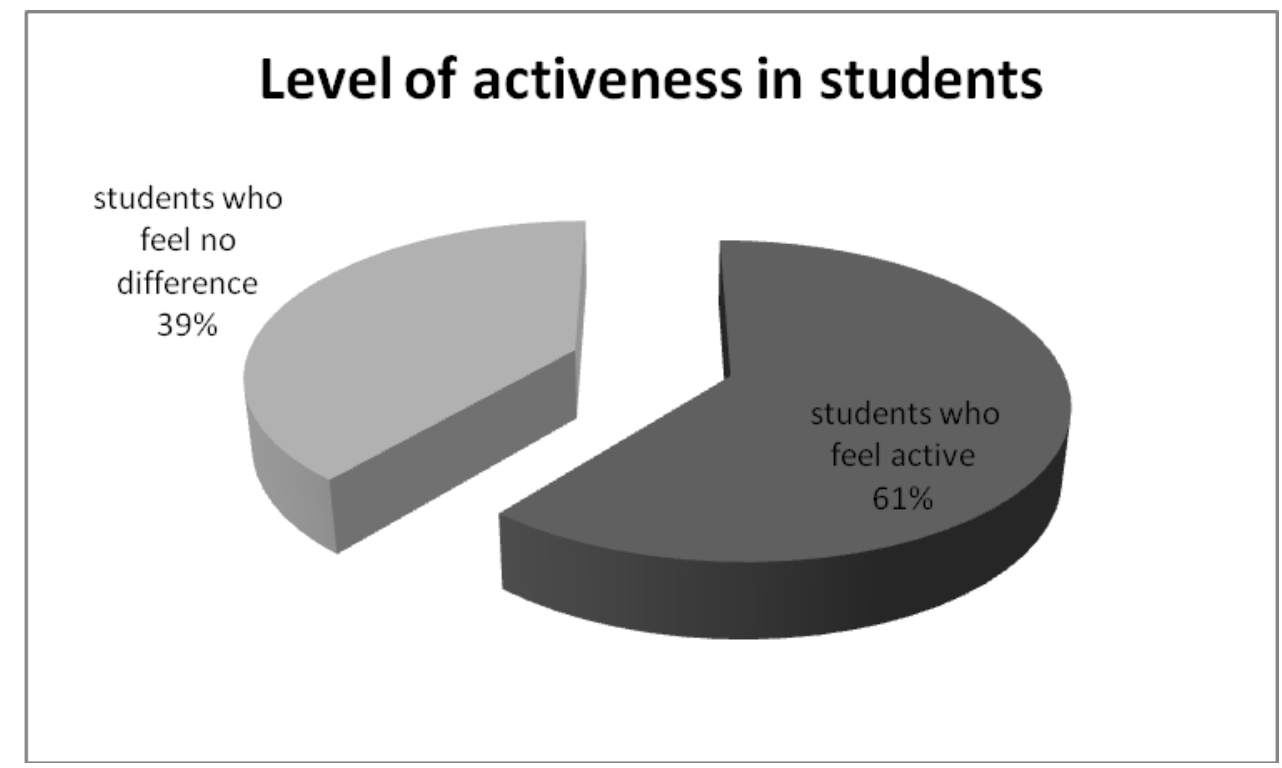

Fig 4.7.Percentage of students who feel active. 


\section{Macrothink}

International Journal of Learning and Development

ISSN 2164-4063 2017, Vol. 7, No. 2

Table 4.8 Percentage of students who understand their lessons better after the intervention.

\begin{tabular}{|l|l|}
\hline better understanding & $57 \%$ \\
\hline
\end{tabular}

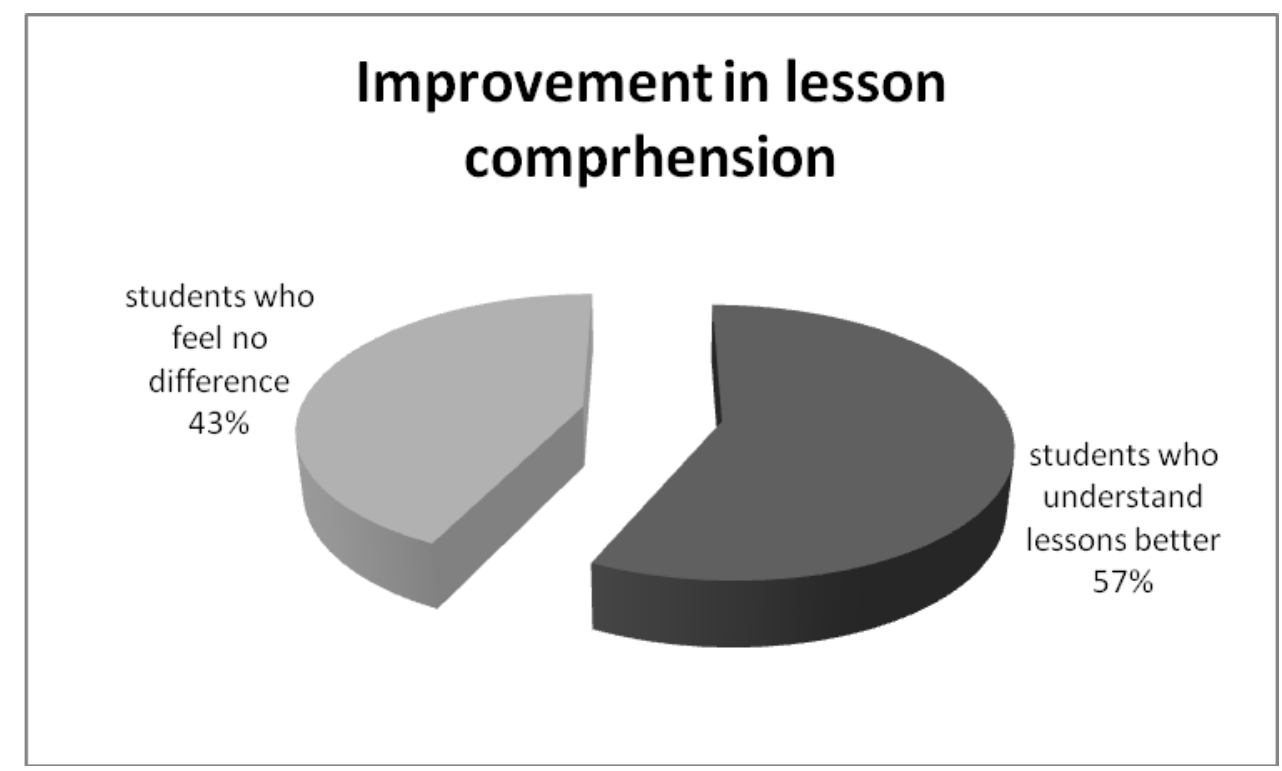

Fig 4.8.Percentage of students who understand their lessons better.

Table 4.9.Percentage of students who want to come to school after intervention.

Since decoration of class I want to $73 \%$

come to school regularly

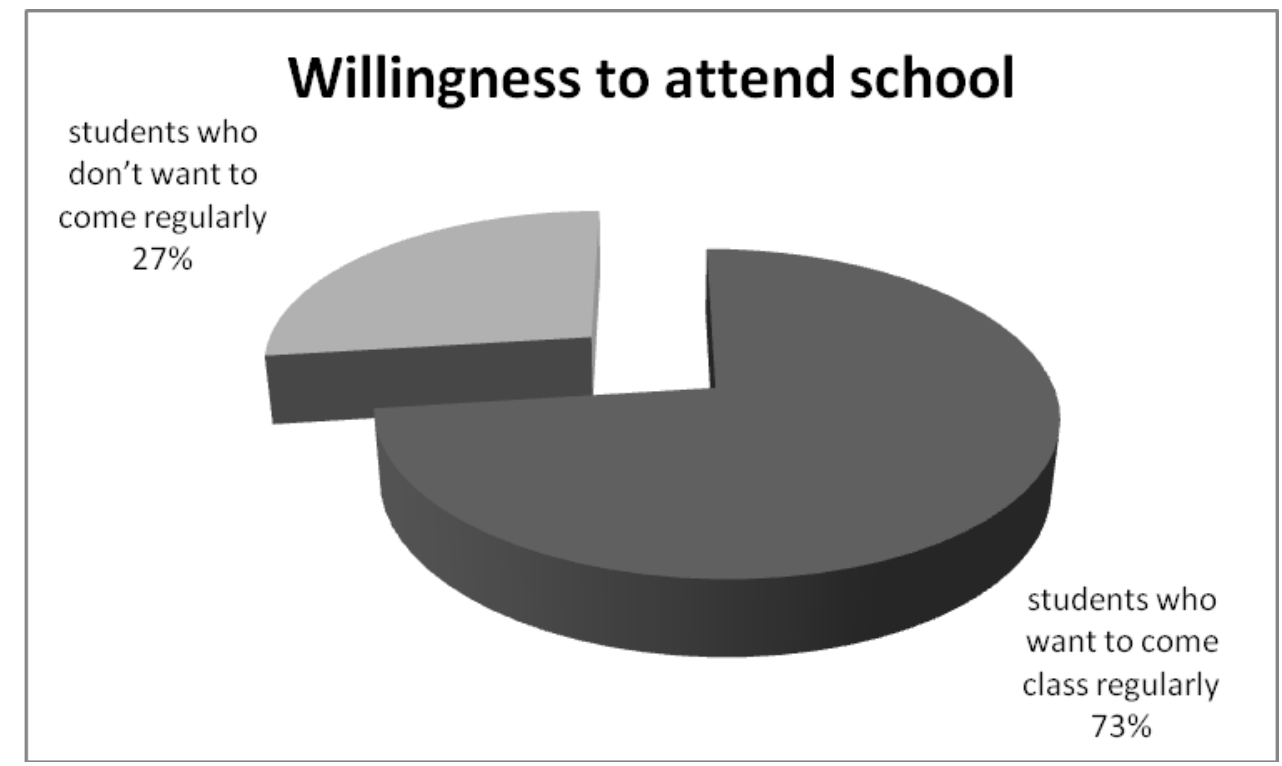


Fig 4.9.Percentage of students who want to attend school regularly.

\subsection{Correlations}

$\begin{array}{ll}\text { Term scores } & \begin{array}{l}\text { Attendance } \\ \text { of students }\end{array}\end{array}$

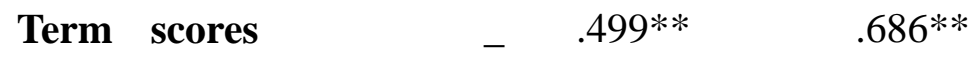

of students

Sig value

(2-taied)

$.000 \quad .000$

Attendance

$.643 * *$

of students

Sig value

(2-tailed)

.000

4.11. Regression color and term scores

$\begin{array}{llllll}\text { Model } & \text { R-square } & \text { F } & \text { Sig } & \begin{array}{l}\text { Sum of } \\ \text { Squares }\end{array} & \text { df } \\ \text { Regression } & .470 & 50.57 & .000 & 9.64 & 1 \\ \text { Residual } & & & & 10.87 & 57 \\ \text { Total } & & & & 20.51 & 58\end{array}$

Predictor $=$ color $\mathrm{Dv}=$ term scores

$\begin{array}{llll}\text { Model } & \begin{array}{l}\text { Unstandardized } \\ \text { Beta Coefficient }\end{array} & \text { t-value } & \text { Sig } \\ \text { Color } & .49 & 1.58 & .000 \\ & .53 & 7.11 & \end{array}$


Dependent Variable $=$ Term scores 
4.12. Regression color and attendance

$\begin{array}{llllll}\text { Model } & \text { R-square } & \text { F } & \text { Sig } & \begin{array}{l}\text { Sum of } \\ \text { Squares }\end{array} & \text { df } \\ \text { Regression } & .41 & 40.19 & .000 & 82.18 & 1 \\ \text { Residual } & & & & 116.56 & 57 \\ \text { Total } & & & & 198.74 & 58\end{array}$

Predictor $=$ color $\mathrm{Dv}=$ attendance

Model

Color

41.07

1.53
Sig

.000

Dependent Variable $=$ attendance 


\section{Macrothink}

\section{Findings}

- $57 \%$ of children reported that they feel they understand their lessons better (table 4.8) as their class decoration helps in reinforcing the concepts taught and also explains the phenomena discussed in the books.

- $73 \%$ of the children reported table (table 4.9) that they want to come regularly to the class after the decorative enhancement of their class.

- A $5 \%$ increase in attendance of female and males was observed in the attendance after the intervention table (table 4.3) and table (table4.1) respectively.

- A $4 \%$ increase in results of students was observed, with 55 students clearing the exams as compared to 51 (table4.5).

- Correlation was checked with Pearson's correlation. (table 4.10), term scores and color correlation was 0.4 and attendance and color was 0.6 since both the values lie within the range, therefore positive correlation exists.

- Linear regression, ANOVA (table 4.11) the value of $F=50.56$ and sig -value is 0.00 which is less then alpha 0.05 , indicates a significant positive relations, the value of $t$ is 7.11 whereas beta is .525 . Since sig-value 0.00 is less than alpha.ie. 0.05 so color scheme has a significant positive effect on term scores of students. (table 4.11), the value of R-square which is 0.470 , a change of $47 \%$ could be explained accurately in dependent variable (term scores of students).

- $\quad$ Linear regression, applied in ANOVA (table 4.12) the value of $F=40.188$ and sig -value is 0.00 which is less then alpha 0.05 , therefore relationship is significant. The value of $t$ is 6.339 and sig-value is 0.00 whereas beta is .686. Since sig-value 0.00 is less than alpha.ie. 0.05 hence color scheme has a significant positive effect on test scores of students. The value of $\mathrm{R}$-square which is $0.41,41 \%$ change is accurately explained in dependent variable (attendance of students).

- To check H1 paired sample t-test was employed, results indicated in (table 4.13) show that $\mathrm{t}=22.2$ and sig-value is 0.000 which is less than $\alpha=0.05$ therefore hypothesis 1 is true .i.e. attendance of students was significantly better after applying color schemes in classrooms. Furthermore the mean of after intervention (Mean=2.69; Standard Deviation=.59) was higher than before intervention (Mean=1.61; Standard Deviation=.49)

- To check H2 paired sample t-test was employed, results indicated in (table 4.14) depicted that $t=16.21$ and sig-value is 0.000 which is less than $\alpha=0.05$ so it means hypothesis 2 is true i.e term scores of students was significantly better after applying color schemes in classrooms. Furthermore the mean of after intervention (Mean=4.74; Standard Deviation=3.04) was higher than before intervention (Mean=3.91; Standard Deviation=1.85) 


\section{Discussion}

This research tests the hypothesis that color has a significant positive impact on child's motivation towards learning. Learning stems from cognitive processes. Jean Piaget presented his theory of cognition which tells how a human child's cognitive processes develop sequentially. He divided a child's cognition development into four stages. The researcher selected the children falling into the concrete operational stage as the child becomes capable of understanding the concepts being taught but this child is still not able to handle the abstract concepts and reasoning and hence effect of color in enhancing motivation toward learning is more easy to establish in this stage owing to the absence of the abstract reasoning prowess. Color in this research was used by the researcher to provide physical stimulations which helped to reinforce the concepts being taught in the class. Color helped children in learning better by becoming a positive stimulus and the colorful decorations done in the class related to the curriculum had a lasting impact on memory of children helping them in learning effectively. $57 \%$ of the respondents reported that they understand their lessons better as supported by Mone (2002) that colored images had lasting impression on human minds as compared to black and white.

Color has different behavioral and psychological implications. Cool colors have a soothing impact on mind and produces relaxing sensations, blue and greens are referred to as cool colors found in Mother Nature. However as discussed in literature overuse of warm colors gives birth to negative energy and hyper activism and excessive use of cool hues produces boredom and stagnation therefore an equilibrium was essential in the use of colors to provide the optimum balance desired by the researcher. For this purpose triad color scheme was selected by the researcher with a liberal use of neutrals for producing myriad of tints and shades. Blue color used in decoration helped to keep students calm, $65 \%$ of the students agreed that blue calms them down. Orange color was used to keep the brains of children awake and to keep them alert and to minimize the effect of blue color so that a positive motivating color scheme would result. $61 \%$ children said their level of activeness has increased since the intervention as supported by (Engelbrecth 2003) and (Torrice and Logrippo 1989). The tests applied in this dissertation explained the color and test score model $47 \%$ accurately and color with attendance model $41 \%$ accurately. The relationship is significant 0.000 at $95 \%$ confidence interval. A $4 \%$ increase in test scores was observed in the student performance as supported by (Allen 2011). Color is an eminent part of a classroom's physical environment. As discussed in methodology of this research colors were used to help children of concrete operational stage learn better by reinforcing the concepts being taught in curriculum. This study analyzed that a significant positive relationship exists between color a component of classrooms physical environment and child's motivation towards learning as by (Suleman and Hussain 2014), that physical environment effect academic scores.

\section{Recommendations}

- Future researchers are recommended to test the impact of other color schemes such as complementary and analogous etc.

- A comparative study could be made out of data collected from rural and urban schools 
to evaluate the similarities and disparities in them.

\section{References}

Allen, B. (2011). The classroom environment: The silent curriculum, California Polytechnic State University San Luis Obispo.

Edwards, C. P. (2002). "Three Approaches from Europe: Waldorf, Montessori, and Reggio Emilia." Early Childhood Research \& Practice 4(1): n1.

Elliot, A. J. and M. A. Maier (2007). "Color and psychological functioning." Current directions in psychological science 16(5): 250-254.

Engelbrecht, K. (2003). "The impact of color on learning." NeoCon, at http://www. coe. uga. edu/sdpl/HTML W 305.

Estes, W. K. (2014). Handbook of Learning and Cognitive Processes (Volume 4): Attention and Memory, Psychology Press.

Inan, H. Z. (2009). "The third dimension in preschools: preschool environments and classroom design." European Journal of Educational Studies 1(1): 55-66.

Karp, E. M. and H. Karp (1988). "Color associations of male and female fourth-grade school children." The Journal of psychology 122(4): 383-388.

Piaget, J. (2000). "Piaget's theory of cognitive development." Childhood cognitive development: The essential readings: 33-47.

Suleman, Q. and I. Hussain (2014). "Effects of classroom physical environment on the academic achievement scores of secondary school students in kohat division, Pakistan." International Journal of Learning and Development 4(1): 71-82.

Torrice, A. F. and R. Logrippo (1989). In my Room: Designing for and with Children, Fawcett Books. 


\section{Macrothink}

International Journal of Learning and Development

ISSN 2164-4063

2017, Vol. 7, No. 2

Mone, G. (2002). "Color Images More Memorable Than Black and White." Scientific American. Retrieved from

www.scientificamerican.com/articel.com/article/color_images_more_memorable/

\section{Copyright Disclaimer}

Copyright for this article is retained by the author(s), with first publication rights granted to the journal.

This is an open-access article distributed under the terms and conditions of the Creative Commons Attribution license (http://creativecommons.org/licenses/by/3.0/). 